\title{
Article
}

\section{Clinical judgement, expertise and skilled coping}

Thornton, Tim

Available at http://clok.uclan.ac.uk/3207/

Thornton, Tim ORCID: 0000-0002-0137-1554 (2010) Clinical judgement, expertise and skilled coping. Journal of Evaluation in Clinical Practice, 16 (2). pp. 284-291. ISSN 1356-1294

It is advisable to refer to the publisher's version if you intend to cite from the work. http://dx.doi.org/10.1111/j.1365-2753.2010.01386.x

For more information about UCLan's research in this area go to http://www.uclan.ac.uk/researchgroups/ and search for < name of research Group>.

For information about Research generally at UCLan please go to http://www.uclan.ac.uk/research/

All outputs in CLoK are protected by Intellectual Property Rights law, including Copyright law. Copyright, IPR and Moral Rights for the works on this site are retained by the individual authors and/or other copyright owners. Terms and conditions for use of this material are defined in the policies page.

\section{CLoK}

Central Lancashire online Knowledge www.clok.uclan.ac.uk

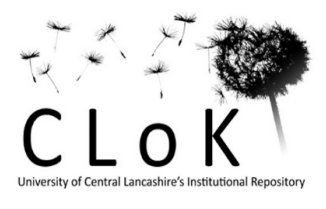


Full Title: Clinical judgement, expertise and skilled coping

Short title: Clinical judgement, expertise and skilled coping

Authors (i.e. name as it should appear on the paper):

Tim Thornton

Position (i.e. job description as it should appear on the paper):

Tim Thornton

Professor of Philosophy and Mental Health and Director of Philosophy

Address for correspondence:

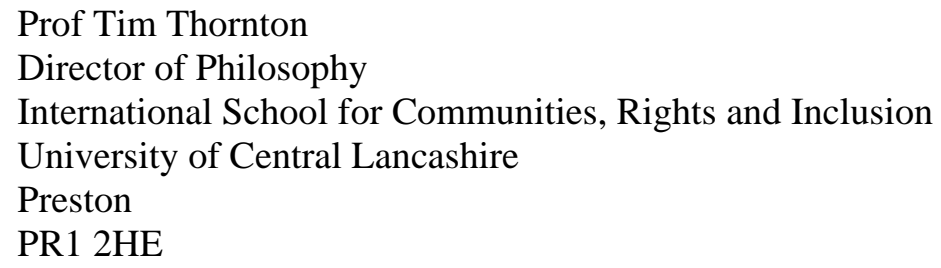

Other Contact Details:

phone $44(0) 1772895412$

fax $44(0) 1772892964$

email:

TThornton1@uclan.ac.uk

Key-words:

Tacit knowledge, clinical judgement, expertise, coping, Dreyfus

Word count (excluding title page but including references):

$\sim 7,100$

Character count (abstract):

Software used: Microsoft Word

Filename(s):

Acknowledgements: There are none 


\section{Clinical judgement, expertise and skilled coping Tim Thornton}

\section{Summary}

Medicine involves specific practical expertise as well as more general context-independent medical knowledge. This raises the question, what is the nature of the expertise involved? Is there a model of clinical judgement or understanding that can accommodate both elements?

This paper begins with a summary of a published account of the kinds of situation-specific skill found in anaesthesia. It authors claim that such skills are often neglected because of a prejudice in favour of the 'technical rationality' exemplified in Evidence Based Medicine but they do not themselves offer a general account of the relation of practical expertise and general medical knowledge.

The philosopher Hubert Dreyfus provides one model of the relation of general knowledge to situation-specific skilled coping. He claims that the former logically depends on the latter and provides two arguments, which I articulate in the second section, for this. But he mars those arguments by building in the further assumption that such situation-specific responses must be understood as concept-free and thus mindless. That assumption is held in place by three arguments all of which I criticise in the next section to give a unified account of clinical judgement as both practical and conceptually structured and thus justified in the face of a prejudice in favour of 'technical rationality'.

\section{Introduction}

Medicine is a practical as well as a descriptive scientific discipline. Medical expertise thus includes context-specific practical skills as well as more general context-independent medical knowledge. This raises the question, what is the nature of the expertise involved? Is there a model of clinical judgement or understanding that can accommodate both elements? Or do the particular practical skills have a different status and nature from the general theoretical framework of medical science? Is there a role for an element of judgement which resists codification in Evidence Based Medicine and if so how does it relate to EBM?

In this paper, I will use a critical examination of Hubert Dreyfus' arguments for the importance of skilled coping to help to articulate elements of an account of clinical judgement. Dreyfus plausibly argues for the importance of one-off, situation-specific, judgement to underpin more general codifications of knowledge. In medicine such codifications are found in statements of EBM. But he mars that claim by assuming that the practical and situation-specific coping must be pre-conceptual and mindless. Correcting that assumption enables one to think of clinical judgement as a conceptually informed capacity which can be expressed both in situation independent general claims as well as particular, situation-specific, practical interventions.

Philosophy has to start from somewhere, however. Thus, in section 1, I summarise some of the findings of a series a ethnographic studies of anaesthetic expertise carried out by Andrew Smith, Catherine Pope and colleagues. They argue, empirically, that clinical expertise in anaesthesia involves a variety of factors including, importantly, a tacit dimension which is often neglected. I will use their descriptions of the features of expertise as a standard for a philosophically informed account. (I will thus not address the potential objection that this is the wrong starting point because the studies are descriptively inaccurate.)

In the second section, I examine the account of skilled coping that Hubert Dreyfus draws both from Martin Heidegger's work and from his own critique of AI-inspired cognitive science. Dreyfus argues that context-specific skilled coping is a precondition of abstract general knowledge. Viewing medical expertise as involving practical skilled coping in Dreyfus' sense would thus be one way to understand the relationship between general medical knowledge and practical skill. 
On Dreyfus' account, however, such coping does not express our conceptually structured understanding. In fact, it is not an expression of a mind at all. As I argue in section 3, this suggests that clinical judgement is implausibly bifurcated into a mindless skill, on the one hand, and mindful conceptual judgement on the other with no sense of how either can inform the other. Further, I will suggest, such an account might undermine the status of such skilled activity if it is characterised as merely mindless.

There is, however, an alternative account available which fits Dreyfus' argument for the priority of situation-based judgement but denies his claim that such judgement is not be conceptually informed. In the fourth section I outline John McDowell's view that concepts can be exercised in context-specific actions even when there is no general and context independent account of the content of those concepts. This gives rise to a conception of clinical judgement as a conceptually informed capacity that finds expression in both explicit, conceptually articulated judgements - general medical knowledge - but also in practical context-sensitive skills. Clinical judgement is thus akin to phronesis.

In what follows I use 'expertise' to refer the findings of the ethnographic studies described in section 1, 'skilled coping' for Dreyfus' semi-technical concept-free notion and 'clinical judgement' as the general intellectual capacity that stands in need of a philosophical account.

\section{1: Expertise in anaesthesia}

Clinical expertise in anaesthesia has been ethnographically examined by a team comprising a consultant anaesthetist, a former anaesthetic nurse and two [1]. In this first section I will draw some of their key findings to set the scene for the philosophical discussion of clinical judgement to come.

Smith et al argue that anaesthesia is underpinned by context-specific knowledge [2]. The main value of their ethnographic approach is that it is able to chart this in addition to, and by contrast with, general context-independent knowledge. Context-specific knowledge is often overlooked, however, because of the dominance of:

'technical rationality' - a model of professional activity as problem solving which is made 'rigorous' by the application of scientific theory and technique. The dominance of technical rationality leaves practitioners unable to account for those aspects of practice that lie outside this model. [2]

Much of the data for their analysis takes the form of field notes and it is worth giving a flavour of this:

The surgeon (S1) discusses patient details with the anaesthetist and asks the age of the patient. The anaesthetist (A1) reads in the notes and says ' 54 '. A1 injects small syringe into the drip and disposes of the empty syringe in the sharps bucket, adjusts the volume of oxygen again, and adjusts the bed having been asked to do so by S1. A1 checks the patient's notes. The ventilator pump is moving and making a slight sound at this point. A1 stands up and begins to write some more details in the notes. One of the green lights is pulsing on and off and is sometimes continuous. There is a pulsing noise fairly regularly but not very loud. Male 1 returns to talk quietly to the A1. I can also hear the diathermy, which is making long beeping noises while the surgeons are operating. A1 sits down watching the patient's head and glancing at the screen on the monitors. She adjusts the oxygen dial. (OB 13: observation of consultant anaesthetist.) [2]

Of this description of a routine gynaecological procedure, they report:

Here, the anaesthetist has available to her a number of types of knowledge. There is knowledge of the patient as a person ('social knowledge') derived from the preoperative visit. There is knowledge from the patient's case notes. She is also gathering knowledge about the patient's physiological progress during anaesthesia from direct observation and indirectly through electronic monitors. Underlying all 
this there is formal theoretical knowledge and the knowledge gained from experience. [2]

This claim highlights the first of four key points which stand out from the descriptive analysis (though the authors do not summarise things in quite this way).

Clinical expertise in anaesthesia involves:

1. a variety of epistemic factors

2. a variety of kinds of skill

3. a sensitivity to specific contexts or situations

4. a sensitivity to specific patients

First, the expertise studied involves the ability to form judgements in the light of a variety of epistemic factors or a variety of sources of information.

A key characteristic of expertise in anaesthesia is the simultaneous balancing of many different streams and types of knowledge. Anaesthetists have to recall what they have learned in the past (both formal learning and previous clinical experiences), and to interpret emerging and potentially misleading electronic signals about the state of the anaesthetized patient. [2]

Thus one aspect is a skill in synthesising different elements. In one example they give, two formal guidelines conflict in a particular case and a skilled clinician has to judge which is the right one to follow in the particular context.

Second, it involves different kinds of skill, including both physical and recognitional skills.

Mental and manual dexterity are required in expert practice, and an ability to recognize and respond to changes in the condition of the anaesthetized patient. This contrasts dramatically with the view of anaesthetic work as largely technical and formulized. [2]

Thus the expertise is not merely an ability to frame explicit judgements on the basis of codified guidelines but also seeing what is the case in particular circumstances and making physical interventions from positioning a patient's head to manipulating complex machinery.

Third, and as already mentioned, it is sensitive to and dependent on specific contexts or situations.

Expertise depends to some extent on its social context and so is vulnerable to changes in that context. This respondent talks about a recent change in his working environment:

You can be an expert in one theatre, and in the next door theatre you may not be an expert, because you are not used to working in that environment. I had been a consultant for $15 \mathrm{yr}$ but I felt like a fish out of water... (Interview with consultant anaesthetist.) [2]

An ability to read the situation in a familiar theatre may not transfer across to others. An ability to read the social cues of one medical team may not carry over to another. This suggests that the form of expertise is, in one important sense, not fully general.

Fourth, in addition to general context dependence it is also highly patient-specific.

I don't need six theatre nurses who have been on an ALS [Advanced Life Support] course telling me what drugs to use. We talk a lot about protocols, we talk a lot about clinical governance, we talk a lot about doing things the same way but I think there is a sense in which that ability to provide appropriate care for a particular patient is lost once you start 'ALS-ing it'. (Interview with consultant anaesthetist.) [2]

Repeated reference was made to the need to tailor anaesthetics to individual patients, and the need for constant vigilance because of the dynamic nature and implicit uncertainty of anaesthesia. [2]

Smith et al even describe one case in which standard general clinical guidelines (proffered by 
a student) are trumped by the patient-specific recognition of a more experienced anaesthetist.

These four features of the expertise described suggest the need for philosophical investigation. How seriously should we take the view that there are different kinds of knowledge involved rather than, for example, different knowledge claims derived from different sources but possible forming a single kind? Is there a connection or a difference of kind between the practical and cognitive?

Whilst the ethnographic investigation of anaesthesia helps to highlight the kind of features that are in play in clinical expertise, it seems to be pitched at the wrong level to answer questions of the nature of the skill or knowledge involved. I suggest that philosophical reflection can also shed some light on the plea with which Smith et al end their paper:

[T]acit forms of knowledge are vital for skilful practice in anaesthesia but are downplayed in formal statements of training. Although by definition tacit knowledge can never be fully articulated, we suggest that anaesthetists should be encouraged to acknowledge the central role of these elements in learning and maintaining their expertise. [2]

One reason that tacit elements of clinical judgement are downplayed in formal training is the rise of Evidence Based Medicine. But, as I will suggest at the end, a proper understanding of clinical judgement helps to unite both tacit elements and the general explicit statements that underpin EBM [cf 3].

\section{2: Dreyfus on skilled coping}

In this section, I will outline Hubert Dreyfus' account of skilled coping. It is based on arguments drawn from two projects. One is his argument against AI-influenced cognitive science. In What Computers Still Can't Do, he argues that the project of modeling intelligence on algorithms or sets of instructions or rules faces a vicious and undermining regress [4]. I will return to the nature of the regress later.

His other project is the interpretation of the philosopher Martin Heidegger's Being and Time. Dreyfus finds in Heidegger the basis for a reorientation of philosophical approaches to knowledge, a reorientation which places embodied practical know-how rather than disinterested context-free 'knowledge-that' at the heart of the analysis. Following Heidegger, he stresses the importance of skilled coping for an account of how it is possible to think about the world at all.

Traditionally, philosophers have assumed that the most basic understanding we have of objects is as mere space occupying stuff. Heidegger argues that our basic stance is practical. Objects are first encountered as tools or equipment with taken for granted uses and purposes. Only given that understanding of what is 'ready-to-hand' can one have a more abstracted understanding of objects now thought of decontextualised from such practical projects and merely as space occupying and 'present-at-hand'.

This stress on the primacy of practical coping and of tacit over explicit knowledge captures some of what Dreyfus finds in Heidegger's approach. But Dreyfus thinks that it forms an important clue to something more fundamental.

It looks like Heidegger thus inverts the tradition and sees detached contemplation as a privative modification of everyday involvement.... But if one simply inverts the tradition, one risks being misunderstood and reappropriated. [5]

Heidegger does not want to make practical activity primary; he wants to show... that neither practical activity nor contemplative knowing can be understood as a relation between a self-sufficient mind and an independent world. [5]

Heidegger sees... that such an account introduces the subject/object distinction. It allows the separation of an intentional content that is mental from an objective world that may or may not be the way the mind takes it to be... Heidegger accepts 
intentional directness as essential to human activity, but he denies that intentionality is mental, that it is... the distinguishing characteristic of mental states. [5]

There is something potentially misleading about thinking of Dreyfus (following Heidegger) as arguing for the primacy of a form of tacit knowledge. The problem is that this risks simply building into a conception of tacit knowledge features of explicit knowledge that Dreyfus thinks are properly thought of as dependent on it. As one commentator puts it:

[I]t would be wrong to say that practical coping involves a 'tacit' understanding embedded in skilful dealings with things. That would mistakenly suggest that skills are already propositionally contentful, even though their content is not explicitly spoken or kept in mind. Dreyfus insists that skilful coping does not even have tacit propositional content. Beliefs, desires, and other propositional attitudes are not appropriately attributed as background to coping skills; instead, Dreyfus argues that propositional attitudes are only intelligible against a background of nonpropositional comportments. [6]

Dreyfus' conception of skilled coping is more basic than might at first be thought. It is not merely that coping is embodied and practical. Coping might be both of those but still be intellectually guided. Dreyfus argues, instead, that it is a form of practical activity which is neither conceptually nor propositionally structured, nor expressive of mental states at all, but on which conceptually or propositionally structured understanding depends.

The crucial distinction is between forms of thought or understanding in which the subject is aware of a distinction between subject and object - 'thematic' understanding - and a more basic immersion in a situation which lacks any such awareness. It is thus a mistake to think of skilled coping as tacit knowledge because:

Knowing is an exemplary subject/object relation, so that if one makes knowing basic, one is from the start locked into the intentionalistic picture of human beings as subjects with beliefs... about objects and states of affairs. [5]

Instead 'all thematic intentionality must take place on a background of transparent coping' [5]. Knowledge, whether explicit or tacit, is derived from a more basic form of situationbased intentionality or coping.

How does skilled scoping help to explain how thematic thought can connect to the world? One answer is that skilled coping directly concerns features of the world. The situation in which one is immersed itself plays a constitutive role in the activity. This contrasts with a key feature of thematic thought. The 'intentional object' of one's propositional attitudes need neither be true nor refer to anything real. One can believe that Father Christmas will call even though 'he' will not, because he does not exist. This is what is meant by the 'intentional inexistence' of the contents of propositional attitudes. By contrast, a skilled pianist's immersion in playing a particular piece of music on a particular piano does not have the potential for a separation from the world implicit in the idea of intentional inexistence. The presence of the piano itself, perhaps a very particular piano, plays an essential role in her activity. Her skilled coping is thus situation-specific.

[P]ractical intentional comportment is not mediated by mental representations, a sensory manifold, tacit rules, or other forms of intentional content abstractable from the material setting of what one is doing. [6]

This idea of situation-specificity also plays a role in Dreyfus' second main argument for the importance of skilled coping based on his critique of using algorithmic AI to model human intelligence. In What Computers Still Can't Do, Dreyfus argues that AI approaches assume that the mind is algorithmic but that they cannot cope with a regress that such an approach initiates [4]. If correct, such an argument would show the importance of a tacit dimension to clinical judgement in addition to whatever can be made explicit in EBM [cf 3].

Dreyfus illustrates the general challenge for AI approaches in the example of attempting to model the behaviour of selecting a red square from a multicoloured array of geometrical 
figures. On an AI approach, there must be a set of instructions that fully capture the expertise involved in the task. And there is a level at which rules may be helpful. One might instruct a child, for example, to 'listen to the instructions, look toward the objects, consider the shapes, make your selection' [4]. But the AI approach would required more detailed instructions sufficient, for example, for identifying a square rather than a circle.

One might say: 'Count the sides; if there are four, it is a square.' And what about the instructions for identifying a side? 'Take random points and see if they fall on a line which is the shortest distance between the end points,' and so on. And how does one find these points?... 'But you unconsciously see points and unconsciously count.' But do you? And why do the instructions stop here and not earlier or later? [4]

The underlying problem highlighted in this example is that of knowing which general rule applies to a particular case. Whilst we know that if something is a red square then it is red and a square and if it is square then it has four equal sides these inferences unpack our prior mastery of the concepts. But the challenge of AI is to explain how such general concepts apply to particular cases: cases which are all alike in being red and square but potentially unlike in all sorts of other ways such as size, location in space and time, orientation etc. But the attempt to explicate a general rule - such as the rule governing 'square' - using further rules appears to initiate a vicious regress. What rules guide the application of the subsequent rules?

If the AI project is to model human intelligence or expertise through algorithms or rules, then the rules cannot leave something important undetermined. If, for example, one claims that the lowest level of rules are themselves automatically followed without instructions then 'we might as well claim that skilled behaviour need not be based on unconsciously followed instructions at any level' [4].

Dreyfus suggests that this regress can be blocked by an appeal to situations.

Whatever it is that enables human beings to zero in on the relevant facts without definitively excluding others which might become relevant is so hard to describe that it has only recently become a clearly focused problem for philosophers. It has to do with the way man is at home in his world, has it comfortably wrapped around him, so to speak. Human beings are somehow already situated in such a way that what they need in order to cope with things is distributed around them where they need it, not packed away like a trunk full of objects... [4]

For humans, the world is first encountered in situations that are already rich in practical significance. Thus the regress attaching to the task of explaining in general terms how general knowledge applies to particular cases is blocked by appeal to direct responses to particular situations. This idea of situations connects back to his other project. The component elements of situations are not isolated objects (present-at-hand) but handy tools or equipment with uses and purposes.

Dreyfus thus presents a picture of skilled coping as a fundamental feature of world-directed activity and thought. Rather than being the poor relative of explicit propositional knowledgethat, it is fundamental. Whilst there could in principle be human tribes who practiced skilled coping but possessed no explicit knowledge, explicit knowledge without skilled coping would be impossible. In the next section I will, however, voice some general criticisms of the bifurcated picture of clinical judgement to which Dreyfus' account of skilled coping leads. This will lead in the fourth section to an articulation of a clinical judgement that is still informed by Dreyfus' argument for the importance of the practical but which spurns his rejection of mediation by concepts.

\section{3: Problems with Dreyfus account for medical expertise}

In the first section I outlined four features of anaesthetic expertise. It involves:

1. a variety of epistemic factors

2. a variety of kinds of skills 
3. a sensitivity to specific contexts or situations

4. a sensitivity to specific patients

Dreyfus' account of skilled coping fits some of these very well and thus it might appear that anaesthetic expertise is just skilled coping in Dreyfus' sense. Like skilled coping, anaesthetic expertise involves context-specific elements. It involves - points 3 and 4 above - both sensitivity to specific contexts or situations and to specific patients.

An operating theatre is a paradigmatic situation in Dreyfus' sense: an environment set up for a particular purpose with, for a skilled clinician, familiar equipment ready-to-hand. A familiar anaesthetised patient is another, albeit animate, part of the situation with a set of interdependent vital systems to be monitored and attended to.

Whilst Dreyfus' account is not directed to interpersonal skilled coping, it dovetails with a plausible approach to interpersonal understanding that would fit anaesthetists working with colleagues. In recent philosophy of mind discussion of knowledge of other people's minds has been dominated by a rivalry between 'theory theory' and 'simulation theory' accounts [7]. According to theory theory approaches, access to, and thus knowledge of, other people's minds is mediated by possession of a theory of mind: a body of deductively structured generalisations about the unseen causes of observable (speech and other) behaviour.

The main contrast with theory theory is simulation theory. It explains knowledge of other minds not by possession of a theory of minds but merely by possession of a mind itself. The idea is that it is possible to have knowledge of another person's mental states by imaginatively putting oneself into his or her predicament. One 'runs' one's deliberative processes 'off line', as it were.

Both these models look too intellectual to fit aspects of the accounts of skilled interaction by clinical teams. By contrast, Dreyfus' description of coping suggests a third possibility. Social coping is itself a non-thematic interpersonal interaction akin to the skilled coping with the non-social environment [cf 8]. This is helped by the fact that Dreyfus himself suggests that the use of words, in skilled coping, need not imply a thematic, propositionally guided understanding. Words can act as tools and be manipulated in the same immersed way as other pieces of (medical) equipment.

Sometimes words are, indeed, used as equipment in the local situation and language functions transparently in a nonpropositional way. In my Commentary I use the example of a doctor, intent on an operation in progress, saying 'scalpel' to her nurse and soon finding one in her hand. [9]

Such social interactions share the same non-thematic, non-propositional character despite their linguistic mediation. (Given that I will reject Dreyfus' account of concept-free skilled coping I owe a suitably direct account of knowledge of other minds. See [10].)

The second feature identified from the ethnographic studies of anaesthesia - point 2 above was the variety of kinds of skills involved. Here the idea of a mix of both manual dexterity and recognitional skills fits Dreyfus' discussion. What does not fit as a case of skilled coping is the more intellectual aspect: the 'mental dexterity' revealed in some of the more explicit judgements. Nor does the remaining feature identified - point 1 above - the simultaneous balancing of many different streams and types of knowledge.

On Dreyfus' account, skilled coping is non-propositional and non-thematic but can give way to propositional and thematic understanding when something breaks down. Paradigmatically, a hammer is transparent when all goes well for the carpenter hammering nails. But if it breaks then it becomes an object for the carpenter's conscious attention, something to be noticed and then dealt with. This is the more typical case for language use. The previous quotation thus continues: 
But often language is used propositionally as when there is some disturbance and the carpenter says that his hammer is too heavy and asks a co-worker to hand him the lighter one. [9]

In fact there are numerous levels described in Being-in-the-World [5]. In the face of a temporary breakdown, skilled coping is forced to give way to acting deliberately, 'paying attention to what we are doing'. When even that is blocked by a more serious disturbance, one is forced into 'still another stance, deliberation. This involves reflective planning' [5]. There are then further stances becoming increasing less immersed less context-specific and more abstract and general. A scientist's theoretical understanding of objects and a traditional philosopher's ontological understanding of them are both yet further from the full immersion of skilled coping. It is only in disturbances of coping or in these yet less contextualised cases of understanding that activity is guided by mental content, by propositionally or conceptually structured awareness.

Dreyfus' Heideggerian comments about the transparency of equipment in skilled coping and its contrasting visibility in cases of breakdown seem to be phenomenologically (with a small p) accurate. But their application to medical expertise would suggest a divided account. According to the model there is, on the one hand, the non-conceptual skilled coping that characterises mindless immersed activity. On the other hand, there is deliberate activity guided by mental states and further context-independent theoretical and minded understanding.

This bifurcation seems implausible, however, as it divides the active employment of skills into those which are movements shared with animals from those which are mindful, conceptually structured actions. Thus there is a strange lacuna in his account when, when things go wrong, conceptual structure springs into being where, despite the recognitional and practical skills previously deployed, there was none, apparently, before. Further, if skilled coping is not expressive of an understanding of the relevant concepts there seems to be no way that it can inform or be informed by explicit conceptually structured judgement.

In the case of medical expertise, this feature of Dreyfus' account has a further strategic disadvantage. In the face of Smith et al's final plea - 'Although by definition tacit knowledge can never be fully articulated, we suggest that anaesthetists should be encouraged to acknowledge the central role of these elements in learning and maintaining their expertise' [2] - Dreyfus' bifurcation of conceptual and non-conceptual elements is more likely to feed the prejudices of what Smith calls ‘technical rationality' and downplay as merely mindless tacit aspects of clinical expertise.

To sum up, Dreyfus provides two arguments for the central role of skilled coping to underpin and augment explicit knowledge. One is based on the idea that the AI-inspired aim to model human intelligence on general rules faces a vicious regress that has to be blocked by appeal to engaged responses to particular situations. General context-independent knowledge must be based on situation-specific responses. The other argument is that world-directed thought must depend on a more basic connection to the world. Skilled coping plays that role but the explanatory requirements placed on it seem to require that it is construed as world-involving but essentially mindless. But as I have argued in this section, that final requirement suggests that it is a poor basis on which to understand clinical judgement.

In the next section I will outline an alternative account building on the discussion of Dreyfus but also based on the work of John McDowell. In the recent debate between Dreyfus and McDowell, it has become clear that a key additional reason that Dreyfus denies that skilled coping is conceptually informed is an assumption about the essential generality of concepts that can be rejected. Rejecting that assumption and rethinking the explanatory requirements for skilled coping allows a more unified account of clinical expertise and judgement. Whilst, as the ethnographic investigation of anaesthesia reveals, core clinical skills are not restricted to the codifications of technical rationality, this does not imply that they are not conceptually structured. 


\section{4: A conceptualised form of context-specific practical knowledge}

The clue to McDowell's account that I will follow is a parallel between skilled action on the one hand and experience on the other. In his book Mind and World, McDowell attempts to give an account of experience that avoids two potential pitfalls driven by two assumptions that appear to be in tension. One assumption is that the ability to have thoughts at all depends on the ability to think thoughts that are empirically based. The world, that is, must have some input to our thought. (This assumption about a worldly input to thought has something in common with Dreyfus' assumption that thematic understanding needs further explanation through world-involving skilled coping.) The other assumption is that thoughts are essentially rationally connected and that this rational connection depends on both elements that are connected being conceptually structured. Our only model of a rational connection is between two conceptually structured entities.

An account of the empirical grounding of thought thus oscillates, according to McDowell, between two opposing but unsatisfactory positions depending on which of the two assumptions dominates. Playing up the second, it can take the form of a coherentist account of thought. A belief is justified if it coheres with our other beliefs, for example. But if so, this picture threatens to undermine any connection between thought and the empirical world. It becomes a frictionless spinning in the void. If an account plays up the first assumption then it may take the form of a commitment to what McDowell following the US philosopher Wilfrid Sellars calls the 'Myth of the Given' [11]. Thought is, indeed, connected to the empirical world but only, impossibly, via brute causal impacts that cannot, in fact, sustain any kind of rational constraint on what we ought to think.

The seesaw can be avoided by crediting experience itself with a conceptual structure. When, for example, we open our eyes, our conceptual capacities are passively drawn on. To articulate this position, McDowell quotes Kant: 'Thoughts without content are empty, intuitions without concepts are blind' [12]. Providing that the intuitions and concepts that together form empirical experiences are not thought of as potentially separable elements of a compound, Kant's slogan forms a clue to a description of experience that avoids the oscillation.

Just as experience is conceptually structured, so, McDowell argues, is the behavioural 'output' of thought. Echoing the Kantian slogan above he says: 'Similarly, intentions without overt activity are idle, and movements of limbs without concepts are mere happenings, not expressions of agency' [13].

So action, like perception, is permeated with conceptual rationality. This underpins McDowell's distinction within what would be for Dreyfus equally examples of skilled but mindless coping of rational and non-rational agents.

When a rational agent catches a frisbee, she is realizing a concept of a thing to do. In the case of a skilled agent, she does not do that by realizing other concepts of things to do... But she does realize a concept of, say, catching this...

When a dog catches a frisbee, he is not realizing any practical concept; in the relevant sense, he has none. The point of saying that the rational agent, unlike the dog, is realizing a concept in doing what she does is that her doing, underr a specification that captures the content of the practical concept that she is realizing, comes within the scope of her practical rationality. [14]

Even an act as spontaneous and context-specific as catching this frisbee now can be part of the narrative of events of a rational agent and fit her concepts of, for example, the right way to spend a summer's morning. Concepts can be exercised in action just as much as they can be in explicit linguistic judgements.

As I have already described, Dreyfus rejects this view. He asks, explicitly and rhetorically:

Can we accept McDowell's Sellarsian claim that perception is conceptual 'all the way out,' thereby denying the more basic perceptual capacities we seem to share with 
prelinguistic infants and higher animals? More generally, can philosophers successfully describe the conceptual upper floors of the edifice of knowledge while ignoring the embodied coping going on on the ground floor; in effect declaring that human experience is upper stories all the way down? [15]

This rhetorical question is, however, backed up by two arguments that are meant to show that McDowell's account of skilled coping cannot be right because such coping cannot be correctly thought of as an exercise of concepts.

One argument has already been mentioned. It is the idea that, unlike explicit thematic thought, skilled coping is essentially situation-specific. The pianist's skilful playing of a piece of music is essentially dependent on the existence of the piano. It would not be the coping it is with either no piano or a very different piano. (It might be something different such as a careful mime act.) By contrast, conceptually structured thoughts can float free of actual situations and concern non-existent states of affairs or objects.

The other argument turns on the generality of concepts. Dreyfus makes this point by considering phronesis. Aristotle distinguished phronesis from general scientific knowledge or episteme and technical knowledge or know-how: techne. Phronesis is practical wisdom: practical in the sense of concerning how to change aspects of the world. That is its intended aim or output and suggests that it serves as a good model for medical practice. But its inputs are particular states of affairs. It is 'concerned with particulars as well as universals, and particulars become known from experience... [thus] some length of time is needed to produce it' [16].

Dreyfus suggest that phronesis is the paradigm case of human perception and action. But he suggests that, on a proper understanding of it, it cannot fit McDowell's conceptualised account. In the exercise of phronesis in making ethical judgements, for example, one simply sees what to do, without deliberation.

As Aristotle says: Phronesis... involves knowledge of the ultimate particular thing, which cannot be attained by systematic knowledge but only by "perception.”... Aristotle's account of phronesis does not assume, as McDowell does, that, ethical expertise can be conceptually articulated. On the contrary, phronesis shows that socialization can produce a kind of master whose actions do not rely on habits based on reasons to guide him. Indeed, thanks to socialization, a person's perceptions and actions at their best would be so responsive to the specific situation that they could not be captured in general concepts. [15]

Neither of these arguments works, however. To take the first, as McDowell is merely one of a number of philosophers who have argued for the importance for an understanding of agents' speech and action of demonstrative thoughts, thoughts tied to particular objects. Thus my thought about that cat sitting on the chair to my left picks out a particular cat in a distinct way from a merely descriptive thought (such as the cat in room such and such ...; or the best cat in the world...) even if, in fact, these pick out the same cat. That is because I may not be aware that I am in room such and such, or that that cat is the best cat. To understand how demonstrative thoughts work is to understand their conceptual content. Thus insisting that skilled coping is situation-specific cannot show that it is not conceptually structured if there are good reasons to hold that conceptually structured thoughts can also be situation-specific.

As to the second argument, Dreyfus assumes that the skilled recognition involved in phronesis in seeing, for example, what ought morally to be done in a particular situation cannot in general be codified. That is, it cannot be captured in context-free general guidelines (akin to what Smith et al call 'technical rationality'). Furthermore, it is plausible that the very idea a conceptually structured understanding is in some sense general. Concepts can be instantiated in more than one way. (Even the concept of being a particular person, being Frege, say, could have been realised by the same man in different ways, had Frege eaten or exercised more, for example. [17]) But phronesis can have the generality of a habit and thus can be general even if the only way to specify its output is a kind of demonstrative. 
No doubt the very idea of a habit implies a generality of content. But conceiving phronesis as a habit, or a set of habits, is consistent with holding that the only way one can register the generality of phronesis is by a description on these lines: 'the habit of responding to situations as phronesis requires'. And that leaves what response a particular situation calls for from the phronimos still needing to be determined by situation-specific discernment. [18]

Dreyfus' account of skilled coping seems to be based on the idea that the exercise of concepts must be explicable in a situation-independent manner. Given that skilled coping is situationdependent, then it cannot be a matter of conceptually informed acting. Hence it becomes merely mindless. There is an irony here. Dreyfus' argument against the pretensions of AI inspired cognitive science turns on their inability to describe the role of a practical responsiveness to situations for human subjects. It is that which enables Dreyfus' account of rational agents to sidestep the worry of a regress of rules in knowing which rule should guide behaviour at any one point. But, it appears, Dreyfus shares with AI an assumption about the nature of conceptual rationality: that it is situation independent. It is that which forces the bifurcation between merely mindless coping and minded exercises of conceptual judgement.

Whilst these arguments help to disarm Dreyfus' two arguments against a concept-involving model of skilled coping, what of the argument described earlier in this paper that such coping must be free of concepts if it is to help explain thematic understanding? Dreyfus' emphasis on skilled coping is part of a broader argument that knowledge, whether contemplative or practical, cannot be 'understood as a relation between a self-sufficient mind and an independent world'. Any account of the mind that starts from world-independent states faces an unanswerable challenge in explaining how they can come to be about anything, to possess intentionality. World-dependent skilled coping is supposed to escape that challenge, as there is no sense to asking whether a pianists' playing concerns a piano, for example. But it is a further and unjustified step to assume, as Dreyfus does, that the coping involved is mindless, is not expressive of a subject's conceptual understanding. Mind and world can be connected in both experience and action, both of which are world-involving, without stripping these of the conceptual shaping which is expressive of minds.

\section{Conclusions for clinical judgement}

Smith and his colleagues highlight some of the aspects of medical expertise found through ethnographic study of anaesthesia. These include a variety of factors from seamless practical manipulations of machinery and patients, through near constant assimilation of a variety of sources of information to explicit discussion with colleagues. They conclude that an important element of this is a form of tacit knowledge which is both of central importance to good clinical practice but also neglected by the emphasis on what they call 'technical rationality' often stressed in medical education. Whilst they do not themselves say this, the emphasis on technical rationality is expressed in, and sustained by, the more general recent rise of Evidence Based Medicine which plays down the role of clinical judgement in favour of general guidelines and codifications of medical practice.

In this paper, I have looked to the work of Hubert Dreyfus to articulate a model of clinical judgement that might help counter that over-emphasis on technical rationality. Dreyfus argues that conceptual and thematic understanding depends on a prior background of situationspecific skilled coping. Thus, according to his arguments, the general articulation of knowledge implicit in EBM presupposes the kind of one-off judgement and situation sensitivity that forms part of good clinical judgement. But Dreyfus assumes that skilled coping is not itself informed by a subject's conceptual capacities. They come into play only in the face of some sort of breakdown of practical skill. Thus whilst Dreyfus' argument helps to counter the prejudice in favour of technical rationality - by arguing for its dependence on a background of situation-specific coping - his account of skilled coping is merely mindless: uninformed by conceptual understanding. This presents an implausible bifurcation within the account of clinical judgement and threatens to provide a further reason to downplay skilled 
coping if it is characterised as merely mindless.

Dreyfus' arguments against the priority of explicit and general knowledge over particular and situation based judgement can, however, be divorced from his account of the latter as concept-free skilled coping. Conceptually structured judgements and actions can be situationspecific. The necessary generality of a concept - the fact that it can be instanced in an open ended variety of ways - need not rule out its context-specificity. On this McDowellian approach, there is no bifurcation between the practical skills, outlined in the case of anaesthesia but characteristic of medicine as a whole, and the explicit clinical judgements that are also an integral part of medical expertise.

Correcting Dreyfus' account suggests instead a unified model of clinical judgement that better fits the description of expertise in anaesthesia. To possess good clinical judgement is to possess a conceptually informed medical understanding. That is not to deny that some clinicians will be better at practical patient-specific interventions and others better at judgements more readily describable in the general terms of EBM. But such differences are differences of degree rather than a difference of kind between conceptual and non-conceptual elements of medical practice. Clinical judgement can be expressed in abstract and contextindependent general claims and also brought to bear on particular situations where the most general thing that can be said is that this (demonstrating an action) is the way things should be done. Although both descriptive and practical, medicine is conceptually structured through and through.

Is there, therefore, a role for an element of judgement which resists capture within the codifications of EBM within good medical practice? Is there anything of that sense of 'judgement' in the description of 'clinical judgement' set out above? I have highlighted three elements of an answer to this question. First: following Dreyfus' argument as corrected in the fourth section, EBM is only possible because of world-directed situation-specific judgements. Second: such judgements are not, however, divorced from general conceptually shaped understanding. (They are not instances of skilled coping in Dreyfus' sense.) Third: there may be no way to express a conceptually mediated situation-specific judgement except by saying: "It should be done like this!" or "Such and such a symptom looks like this!" Given that such judgements cannot be framed in general context-free terms there is indeed a role for the traditional understanding of clinical judgement even within contemporary Evidence Based Medicine. 


\section{References}

1 Pope, C., Smith, A., Goodwin, D. and Mort, M. (2003) Passing on tacit knowledge in anaesthesia: a qualitative study. Medical Education, 37, 650-655

2 Smith, A., Goodwin, D., Mort, M. and Pope, C. (2003) Expertise in practice: an ethnographic study exploring acquisition and use of knowledge in anaesthesia. British Journal of Anaesthesia, 91, 319-28

3 Thornton, T. (2006) Tacit knowledge as the unifying factor in EBM and clinical judgement. Philosophy Ethics and Humanities of Medicine, 1:2 doi:10.1186/17475341-1-2

4 Dreyfus, H.L. (1999) What Computers Still Can’t Do, Cambridge, Mass.: MIT Press

5 Dreyfus, H.L. (1991) Being-in-the-World: A Commentary on Heidegger's Being and Time, Division I, Cambridge, Mass.: MIT Press

6 Rouse, J. (2000) Coping and its contrasts. In Heidegger, Coping, and Cognitive Science (eds M. Wrathall and J. Malpas), pp. 7-28. Cambridge, Mass.: MIT Press

7 Carruthers, P. and Smith, P.K. (eds) (1996) Theories of theories of mind, Cambridge: Cambridge University Press

8 Ratcliffe, M. (2008) Rethinking Commonsense Psychology, Basingstoke: Palgrave Macmillan

9 Dreyfus, H.L. (2000) Responses. In Heidegger, Coping, and Cognitive Science (eds M. Wrathall and J. Malpas), pp. 313-349 .Cambridge, Mass.: MIT Press

10 Thornton, T. (2004) John McDowell, Chesham: Acumen

11 Sellars, W. (1997) Empiricism and the philosophy of mind, Cambridge, Mass.: Harvard University Press

12 Kant, I. (1929) Critique of Pure Reason (translated by Kemp Smith, N), London: Macmillan

13 McDowell, J. (1994) Mind and World, Cambridge, Mass.: Harvard University Press

14 McDowell, J. (2007) Response to Dreyfus. Inquiry, 50, 366-370

15 Dreyfus, H.L. (2006) Overcoming the myth of the mental. Topoi, 25, 43-49

16 Aristotle (1985) Nicomachean Ethics (translated by Irwin, T.), Indianapolis: Hackett

17 Travis, C. (2007) Reasons' reach. European Journal of Philosophy, 15, 225-48

18 McDowell, J. (2007) What Myth? Inquiry, 50, 338-351 